\title{
Executive Function Patterns in Children with Autism Spectrum Disorder (ASD)
}

\author{
Muchamad Irvan \\ Department of Special Education \\ Universitas Negeri Malang, Indonesia \\ muchamad.irvan.fip@um.ac.id
}

\begin{abstract}
The purpose of this study was to analyze patterns of executive function disorder of children with ASD in several age ranges. Age ranges focus that have been studied are preschool age, school age, and adult age. The analysis was conducted to the executive function literature that examine at a specific age range. Coding is arranged based on the executive function definition to facilitate the analysis process. There are 6 references that are critically analyzed and pass the screening stages according to the prerequisite criteria. The conclusion drawn from the analysis is that executive function disorder in ASD children is dominant in the aspects of flexibility and inhibition. The difficulties in other aspects are planning, working memory, emotional control, and performance.
\end{abstract}

Keyword: autism spectrum disorder, executive function

\section{INTRODUCTION}

Generally, humans have the ability to design and carry out an activity that related to other activities based on specific objectives (Banich, 2009). This ability is one of cognitive abilities that called executive functions. The executive function is the umbrella of a group of cognitive processes that can directly affect behavioral goals, provide control over self-management, and emotional control (Yerys et al, 2006). Executive functions include problem solving skills, managing schedule changes (Ozzonof \& Jensen, 1999), controlling behavior, organizing, planning, memory performance, and managing emotions (Hadar et al, 2017). Other experts also argue that executive function is a complex arrangement of cognition in formulating various associative processes through high-level thinking and behavior that develops throughout life (Yerys et al., 2006; Dai et al., 2018; Johnston et al., 2019; Hutchison , Muller, \& Grace 2019). Nonetheless, the ability of executive functions in humans can also be affected by various conditions including aging, disease (Alzheimer's, bipolar, etc.), or there are neurodevelopmental problems (Banich, 2009; Johnston et al, 2019).

Various studies suggested that individuals with neurodevelopmental disorder most indicate problems in executive functions, for example, Attention Deficit Hyperactive Disorder (ADHD), Obsesive Compulcive Disorder (OCD), and Autism Spectrum Disorder (ASD) (Ozzonof \& Jensen, 1999; Dvorsky \& Langberg, 2014; Hadar et al., 2017; Hutchison, Muller, \& Grace 2019). However, children with ASD have the most complex neurodevelopmental problems among others.

This condition is characterized by stunted developments in aspects of communication and interaction skills, and shows limitations on interests (called restricted) and repetitive behavior (called repetitive) (American Psychiatric Association 2013; Irvan, 2017). Basically, children with ASD have difficulty interacting and communicating with the social environment (Hutchison, Muller, \& Grace 2019), and exhibiting stereotypical behavior (Vries \& Geurts 2015). Children with ASD is a neurodevelopmental disorder that has pervasive disorder that are very attached (Vries \& Geurts 2015). Children with neurodevelopmental disorders generally have executive function problems (Ozzonof \& Jensen, 1999).
Based on these problems, this study aims to examine the ability of executive functions in children with ASD. Previous studies have discussed executive functions in children with ASD, for example at the age of 3.5-4 years (Yerys et al, 2006), 8-12 years (Vries, 2015), 6-13 years (Hutchison, Muller, \& Grace 2019), adolescents (Johnston et al, 2019). However, it still needs to be reanalyzed from various previous studies to be able to infer about the condition of executive function abilities in children with ASD at each age level including preschoollers, schoollers, and adults.

\section{METHOD}

Literature review of studies conducted by collecting various online sources in Springer and SagePub sites. The keywords used are Executive Function (EF) and Autism Spectrum Disorder (ASD). Citation is generalized on the first search, then screened through the title, abstract, and content exposure to get more specific results. Filtering is applied based on inclusive and exclusive criteria. The criteria required in each article must be 1) is the result of research on executive functions in children with ASD; 2) is a study conducted at pre-schoollers, schoollers, or adults. Whereas exclusive criteria is applied to articles that do not speak English.

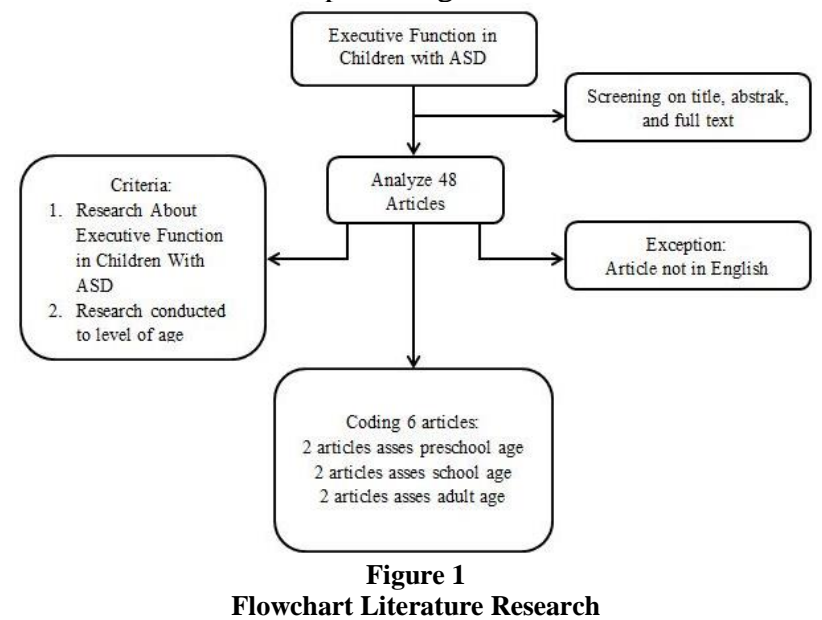

Critical assessment is carried out to select each source to maintain the quality of the data obtained. Furthermore, the data from selected sources are analyzed. The stages are carried out by making Coding in 
accordance with the criteria of the executive functions ability. Thus, a common thread can be drawn about the disruption of the executive function of children with ASD.

\section{RESULTS}

Stages of this literature study begins with searching for resources using the keyword executive function, then pursed using the keyword executive function in children with ASD. A search using the Executive Function keyword returned more than 480 related articles. Furthermore, keywords are more focused by using the keyword Executive Function in children with ASD resulting in more than 100 similar articles. However, after screening based on the title only got 48 articles that met the first criteria (research that was only conducted on children with ASD). Meanwhile, the screening process did not find articles that were not in English, so the exclusion criteria were not found.

After initial screening, proceed to re-select the sources obtained to produce a specific data source (see prerequisite criteria in the method section). This stage resulting 6 literature that meet the criteria for analysis (Figure 1), Preschollers literature: Valeri, et al. (2019) and Yerys, et al. (2006), Schoollers literature: John (2017) and Blijd (2014), Adult literature: Johnston (2019) and Brady (2017). Content analysis of these sources uses Coding selected based on the results of data triangulation of previous research. Based on results of the triangulation of Executive Function definitions, it is found that coding working memory, planning, inhibition, flexibility, emotional control, and performance.

Working memory is defined as the processing of information into a sequence of specific activity (Ozonoff $\&$ Strayer, 2001). Planning is defined as the ability to sort and organize activities to be carried out (Brady, et al. 2017; Weyandt \& Dupaul, 2013). Inhibtion is defined as the ability to control behavior that may arise and disrupt daily activities (Brady, et al. 2017). Flexibility is defined as the ability to understand a group of daily tasks and the ability to change the order of certain activities (Banich, 2009). Emotional Control is defined as the ability to control the behavior of emotional conditions in order to remain in the goal of activity (Hadar, et al. 2017). While Performance refers to self-regulation and individual consistency in carrying out daily tasks (Drowsky \& Langberg, 2014).

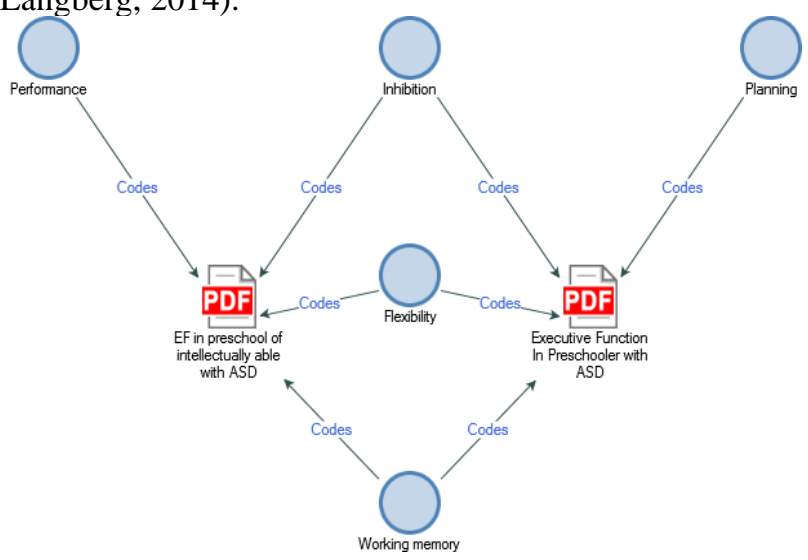

Figure 2

Preschoollers Coding
Figure 2 shows the agreement of the results of research on executive function disorders in children with ASD preschool age. Based on the results of the content analysis there are 3 agreement results that are grouped in Coding working memory, flexibility, and inhibition. However, Valeri et al. (2019) and Yerys, et al (2006) have different agreements on other aspects, namely coding planning and performance.

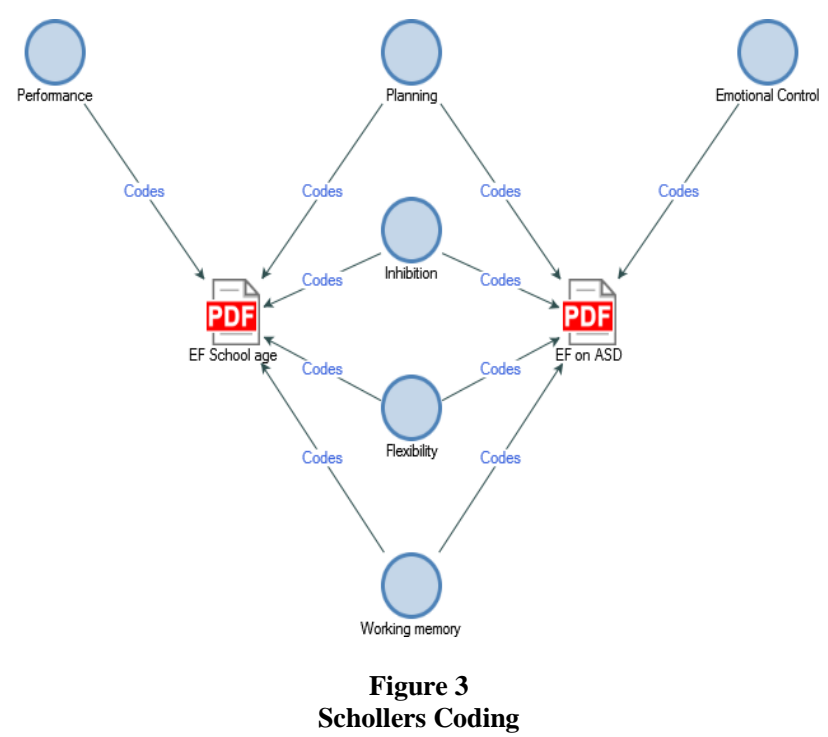

The equation in Figure 2 and Figure 3 is the Coding agreement on aspects of working memory, flexibility, and inhibition. However, Figure 3 shows the Coding agreement on other aspects not found in the preschool age analysis, namely the planning aspect. Content analysis of the results of research John (2017) and Blijd (2014) also indicate a disagreement about emotional control and performance aspects. Blijd (2014) emphasizes the indications of problems in emotional control, while John (2017) does not state that, in other words emphasizing performance aspects.

Coding in the aspects of working memory, flexibility, and inhibition also got an agreement on the results of Johnston's (2019) and Brady's (2017) research. While, disagreement lies in the aspects of emotional control and working memory. Therefore, the adult level has similarities in the previous levels which emphasizes that the problem of the executive function lies in the aspects of working memory, flexibility, and inhibition. However, at the adult level there was no discussion of performance in the case of executive functions of children with ASD.

\section{DISCUSSION}

This study examines a variety of previous research literature on the ability of executive function in children with ASD. The study was conducted by analyzing the literature related to the ability of executive functions of children with ASD at a certain age range. The prerequisite criteria are applied to narrow the focus of the literature analysis. After screening from source tracking, 6 literatures were selected that best fit the boundaries applied (two preschoollers literature, two schoollers literature, and two adult literature).

Based on the results of the analysis, that children with ASD at preschool age have problems in the aspects 
of inhibition, working memory, and flexibility. These aspects are most dominant as problem patterns in the executive function abilities of children with ASD. However, Valeri et al. (2019) and Yerys, et al (2006) have different opinions about aspects of performance and planning. This fact occurs because of differences in subject research. The theory underlying the differences in these findings is because children with ASD have characteristic symptoms that vary from one another (Koray, 2011; Irvan \& Jauhari, 2017). Vries and Hilde (2015) state that the ability of executive functions at preschool age is still not developing optimally. Therefore, children at preschool age showed less ability to plan various activities in sequence.

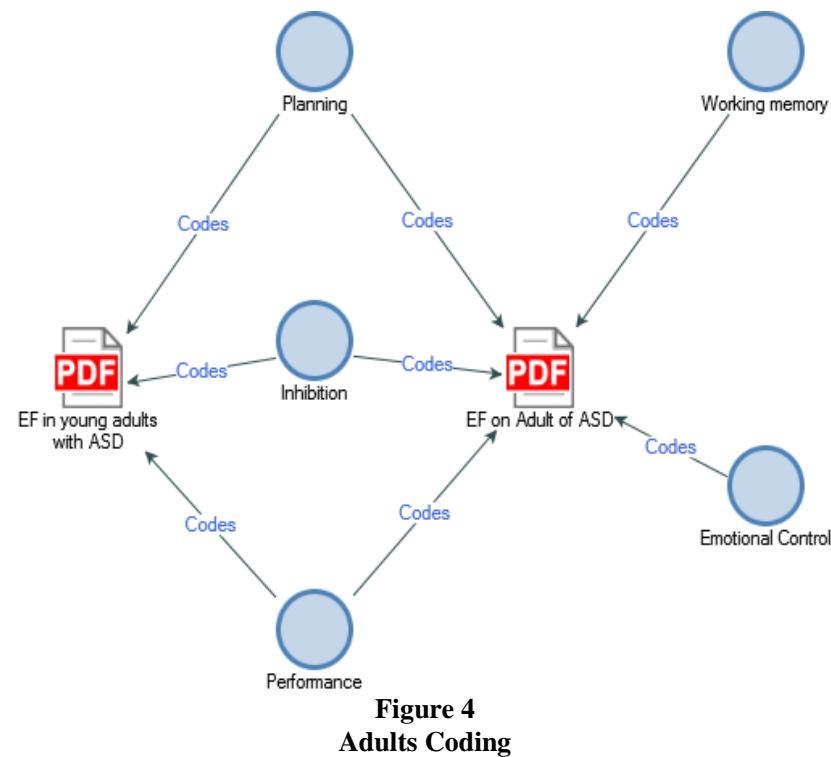

Furthermore, in students with ASD, both literatures state that the problem of executive function ability is dominant in four aspects. John (2017) and Blijd (2014) have found that planning problems become dominant at this level. However, Blijd (2014) found that the problem of executive function of children with ASD at school age was also shown by poor emotional control. This finding is based on that children at school age should be able to control emotional conditions in certain conditions, for example at this time has passed the tantrum or meltdown. This aspect is closely related to the aspect of inhibition, where this ability aims to be able to control the obstacles that arise from within and problem solving.

Whereas at the age level of adult was found different conditions from the previous age level. Both the literature (Johnston, 2019; Brady, 2017) suggests that the problem of executive function of children with ASD adult age levels occurred more frequently in aspects of inhibition, planning and performance. Not all children with ASD showed problems in the aspects of working memory and emotional control Johnston (2019). This condition can occur due to educational factors that shape the ability of children to empower emotional control and working memory properly.

Thus it can be concluded that, the problem of executive function in children with ASD appears with almost the same pattern in every age range. These conditions can be different due to several factors including, intelligence, intervention models, stages of cognitive development, or differences in the executive function assessment standards.

Research Limitation

Limitation of research is applied to study this case. First, this study is limited to previous findings about the executive function of children with ASD and aspects of the dominant problem at a certain age range. Second, this study was conducted by analyzing the contents of the literature which examines the interference pattern of executive functions.

Further, research must provide more detailed boundaries to get more specific results. Further studies should be able to impose limits on the methods applied in classifying the pattern of executive function of children with ASD from previous researchers. This effort was made to reduce bias due to different methods or due to different scales used to measure executive funtions.

\section{REFFERENCES}

[1] American Psychiatric Association. 2013. Diagnostic and Statistic Manual of Mental Disorders. Arlington, VA: American Psychiatric Publishing.

[2] Banich, Marie T. 2009. Executive Function: The Search for an Integrated Account. Journal of Current Directions in Psychological Science, 18(2), 89-94.

[3] Brady, Danielle I. et all. Executive Function in Young Adult With Autism Spectrum Disorder. Journal: Focus on Autism and Other Developmental Disabilities, 32(1), 3134.

[4] Blijd, E.M.A. et all. 2014. Executive Function in Children with ASD: An Anlisys of the BRIEF. Journal of Autism and Developmental Disorders, 44, 3089-3100.

[5] Dai, Meixia. et all. 2018. Gender Difference in the Association Between Executive Function and Autistic Traits in Typically Developing Children. Journal of Autism and Developmental Disorders, 49, 1182-1192.

[6] Dvorsky, Melissa R. Langberg, Joshua M. 2014 Predicting Impairment in College Students With ADHD: The Role of Executive Functions. Journal of Autism and Developmental Disorders, 23(13), 1624-1636.

[7] John, Tanya St. Dawson, Geraldine. Annette Estes. 2017. Breif Report: Executive Function as a Predictor of Academic Achievment in School-Aged Children with ASD. Journal of Autism and Developmental Disorders, 48, 276-283.

[8] Hadar, Yaffa. et all. 2017. Auditory and Visual Executive Function in Children and Response to Methylphenidate: A Randomized Controlled Trial. Journal of Attention Disorders, 23, 1-11.

[9] Hutchison, Sarah M. Muller, Ulrich. Grace Larocci. 2019. Parent Reports of Executive Function Associated with Functional Communication and Conversational Skills Among School Age Children With and Without Autism Spectrum Disorder. Journal of Autism and Developmental Disorders, 25, 1-9.

[10] Irvan, Muchamad. 2017. Gangguan Sensori Integrasi Pada Anak dengan Autism Spectrum Disorder. Journal of Buana Pendidikan, 13(2), 1-9.

[11] Irvan, Muchamad. Jauhari, Muhammad Nurrohman. 2017. Early Intervention For Children With Autism Spectrum Disorder Using Planning Matrix. University of PGRI Adi Buana Surabaya: ICETA.

[12] Johnston, Kate. et all. 2019. Executive Function: Cognition and Behaviour in Adults with Autism Spectrum 
Disorder (ASD). Journal of Autism and Developmental Disorders, 49, 4181-4192.

[13] Koray, Karabekiroglu. 2011. Pervasive Developmental Disorder-Not Otherwise Specified: Specifying and Differentiating. Ondukuz Mayis University. Turkey.

[14] Ozonoff, Sally. Jensen, Jenise. 1999. Brief Report: Specific Executive Function Profiles in Three Neurodevelopmental Disorders. Journal: Autism and Developmental Disorders, 29(2), 171-177.

[15] Ozonoff, Sally. Strayer, David L. 2001. Further Evidence of Intact Working Memory in Autism. Journal: Autism and Developmental Disorders, 31(3), 257-263.

[16] Valery, Giovanni. et all. 2019. Executive Function and
Symptom Severity in on Italian Sample of Intellectually Able Preschoollers with Autism Spectrum Disorder. Journal: Autism and Developmental Disorders.

[17] Vries, Marieke de. Geurts, Hilde. 2015. Influence of Autism Traits and Executive Functioning on Quality of Life in Children with an Autism Spectrum Disorder. Journal: Autism and Developmental Disorders, 45, 27342743.

[18] Yerys, Benjamin E. et all. 2006. Executive Function in Prescholers with Autism: Evidences Consistent with a Secondary Deficit. Journal: Autism and Developmental Disorders,

37,

1068-1079. 